\title{
Constructive methodological deflationism, dialetheism, and the Liar
}

Document Version

Accepted author manuscript

Link to publication record in Manchester Research Explorer

\section{Citation for published version (APA):}

Liggins, D. (2014). Constructive methodological deflationism, dialetheism, and the Liar. Analysis, 74(4), 566-574. https://doi.org/10.1093/analys/anu087

\section{Published in:}

Analysis

\section{Citing this paper}

Please note that where the full-text provided on Manchester Research Explorer is the Author Accepted Manuscript or Proof version this may differ from the final Published version. If citing, it is advised that you check and use the publisher's definitive version.

\section{General rights}

Copyright and moral rights for the publications made accessible in the Research Explorer are retained by the authors and/or other copyright owners and it is a condition of accessing publications that users recognise and abide by the legal requirements associated with these rights.

\section{Takedown policy}

If you believe that this document breaches copyright please refer to the University of Manchester's Takedown Procedures [http://man.ac.uk/04Y6Bo] or contact uml.scholarlycommunications@manchester.ac.uk providing relevant details, so we can investigate your claim.

\section{OPEN ACCESS}




\section{Abstract expressionism and the communication problem}

\section{DAVID LIGGINS}

Abstract. A number of philosophers have recently suggested that the reason mathematics is useful in science is that it expands our expressive capacities. Of these philosophers, only Stephen Yablo has put forward a detailed account of how mathematics brings this advantage. In this paper, I set out Yablo's view and argue that it is implausible. Then I introduce a simpler account and show it is a serious rival to Yablo's.

\section{Introduction}

2 Yablo's expressionism

3 Psychological objections to Yablo's expressionism

4 Introducing belief expressionism

5 Objections and replies

5.1 Yablo's likely response

5.2 Charity

6 Conclusion

\section{Introduction}

Any philosophy of mathematics must explain what Eugene Wigner [1960] called the 'unreasonable effectiveness of mathematics'. We naturally think that empirical science aims to understand physical objects - planets, trees, mice, molecules, and atoms, for example. All these things seem to be spatially located and causally active. If there are mathematical objects, such as numbers and sets, they do not have this character. So why do our best scientific theories apparently refer to them? For instance, our best astronomical theories include the claim:

(S) The surface area of Saturn, measured in $\mathrm{km}^{2}$, is $1.08 \times 10^{12}$. 
Why did an inquiry into physical objects end up mentioning 1.08×1012 (a number)?1

Those who believe in mathematical objects can go a long way towards explaining this phenomenon by claiming that, though empirical science studies objects like planets and molecules, it has discovered that these objects bear relations to numbers. On this approach, $(\mathrm{S})$ is read as claiming that Saturn and $1.08 \times 10^{12}$ stand in the surface-area-in- $\mathrm{km}^{2}$ relation. More generally (the explanation goes), facts about quantities are facts about relations between physical objects and mathematical ones. Since scientists are interested in how massive things are, what temperatures they have, how big they are, and so on, and in laws that relate these quantities, it is no surprise that science abounds in reference to mathematical objects.

This explanation might turn out to be unsatisfactory, even if there are mathematical objects. But its availability means that those who do not believe in such things ought to provide an alternative. A number of philosophers have recently accepted this challenge. They suggest that the reason mathematics is useful in science is that it expands our expressive capacities:

In short, mathematics appears in our empirical theories as a mere descriptive aid: by speaking in terms of the real number line, ... or some other mathematical structure, we simply make it easier to say what we want to say about the physical world. (Balaguer [1998], p. 137)2

Numbers enable us to make claims which ... we ... would otherwise have trouble putting into words. (Yablo [2002] p. 230)

1 Wigner's original explanandum was more restricted: 'the appropriateness of the language of mathematics for the formulation of the laws of physics' ([1960], p. 14). But the scientific utility of mathematics extends beyond physics and beyond the formulation of laws - as (S) makes plain.

2 Strictly speaking, Balaguer is not an expressionist, though he has sympathetically discussed the doctrine. Take 'Balaguer' to mean 'any defender of the philosophy of mathematics articulated and defended in chapters 5 and 7 of (Balaguer [1998])'. For a related view, see (Leng [2010]). 
[M]athematics is used [in science] simply in order to make more things sayable about concrete objects [i.e. spatially located and causally active entities]. (Melia [1998] pp. 70-1; see also Melia [1995], [2000])

This trend deserves a name. Let abstract expressionism be the doctrine that mathematics is useful in science because it helps us to say things about concrete objects which it would otherwise be more difficult, or perhaps impossible, for us to say. For brevity, I'll just call the view 'expressionism'. I should mention that expressionism is not a form of non-cognitivism and is unrelated to metaethical expressivism. It is worth stressing that abstract expressionism is a theory about why mathematics is actually useful in science, not a revisionary proposal of any kind. It is possible to believe in mathematical objects whilst endorsing expressionism: such a philosopher would not appeal to mathematical objects in explaining the scientific utility of mathematics. But here I'll concentrate on forms of expressionism which do not posit mathematical objects. In fact, I will concentrate on nominalist abstract expressionism: that is, abstract expressionism coupled with the denial that there are any mathematical objects.

Abstract expressionism immediately faces a serious challenge. It is arguable that mathematics in useful in science in several ways: for instance, it enables us to draw inferences about scientific matters, and helps us to make new scientific discoveries. It could well be argued that mathematics is also crucial to scientific explanation (see e.g. Colyvan [2002]). Considering these phenomena, it seems doubtful that the mathematics used in science should be regarded as 'mere descriptive aid'.

Melia ([2002]) responds to the point about the explanatory role of mathematics: he argues that, for all Colyvan has shown, mathematics is useful in explanation only because of its expressive role. Perhaps this strategy can be carried over to other cases in order to meet the challenge. I will not consider that issue here. Rather, I will examine the expressionists' claim that mathematical language expands our expressive capacities, as I will now explain.

Mathematical language would not be a very good 'descriptive aid' if it allowed us to express 
our beliefs about the physical world only in a way that no-one else could understand. So when expressionists say that mathematical language expands our expressive capacities, they must mean that it helps us communicate.

This cannot be the end of their explanation. Astrological language also expands our expressive capacities and helps us to communicate astrological beliefs. Presumably expressionists will say that mathematical language differs from astrological language in that it helps us to communicate truths. Expressionists who do not believe in numbers will say that these truths are nominalistic - that is, they do not entail the existence of numbers or other mathematical objects.

If mathematical language helps us to communicate such truths, there must be a story to be told about how it provides it. The phenomenon is not plausibly regarded as a brute fact. Consequently, expressionists ought to provide us with an account of how this communication takes place. If expressionists are unable to provide a credible account, then their philosophy of mathematics will be unworthy of acceptance. Let us call this the communication problem for expressionism.

So far, Stephen Yablo is the only expressionist to have offered a detailed solution to the communication problem. 3 The purpose of this paper is to suggest a rival solution for expressionists, which has some advantages over Yablo's and may turn out to be superior to it.4 For simplicity, I concentrate on the case of arithmetic. After laying out Yablo's explanation (section 2), I argue that it is psychologically implausible (section 3). I then introduce a much simpler form of expressionism-

3 Balaguer ([1998: 138]) appeals to sameness of structure to solve the problem: the real numbers are helpful in ascribing temperature properties to physical objects because the space of possible temperature states is homomorphic to the real numbers. Whilst I do not dismiss this approach, I should point out that it requires further development before it can be properly evaluated, for it is not the case that structural similarity is enough to explain communicational success. There is no reason to expect a claim about an object's length to convey information about its temperature, even if the space of possible lengths is isomorphic to the space of possible temperatures. Similarly, claiming that this coin has landed heads conveys no information about whether that coin has landed heads.

4 Yablo's contribution to the philosophy of mathematics is not confined to his explanation of the utility of mathematics in science, but that is my focus here. 
belief expressionism - and show how it can explain how mathematics provides us with expressive advantages. I argue that belief expressionism demands to be regarded as a serious rival to Yablo's account (section 4). Finally, I rebut a number of objections, and show how the belief expressionist can undermine the case Yablo makes for his view (section 5).

I will pause here to note that this debate is relevant to the success of Hartry Field's wellknown account of mathematics. Field does not claim that mathematics expands our expressive capacities;5 rather, he claims that mathematics enables us to reason more efficiently. Given nominalistic premises and conclusions, the most efficient way to deduce the latter from the former often involves mathematics, as Field emphasises. But our current scientific theories are not nominalistic: as we have seen, they include claims like (S), which imply the existence of numbers. Field therefore provides us with no explanation of why mathematics is currently useful. Since his view will not be tenable unless an explanation of this phenomenon is added (see Yablo [2005] pp. 91-3), Field has some motivation to adopt abstract expressionism.

\section{Yablo's expressionism}

According to Yablo, mathematical talk is figurative rather than literal. More specifically, he believes that mathematical claims are metaphors, like 'No man is an island', or 'Juliet is the sun'. This view is a natural one for an expressionist, since it seems that metaphors expand our expressive capacities. Yablo cites an example which makes the point nicely. We often call clouds 'angry', although we are aware that clouds have no emotional life at all. Although these predications are never literally true, they do manage to convey something about the nature of the clouds we are describing. And it seems that it is much more cumbersome to communicate these claims in a straightforward and literal fashion. The best we can do relies on the imagery: instead of calling a cloud 'angry', say it is 'such that it would be natural and proper to regard [it] as angry if one were going to attribute emotions to clouds' (Yablo [1998], p. 250).

5 At least, he does not claim this in his ([1980]) or ([1989]). More recently, though, he has begun to sound sympathetic to expressionism: see (Field [1998], pp. 329-30). 
Yablo elaborates his position by adopting a theory of the nature of metaphor inspired by (Kendall Walton [1993]). Walton uses the notion of a principle of generation, which links what is the case according to a game of make-believe with what is really the case. 6 For example, suppose we are children, passing our lunch break by pretending to fight the Battle of Hastings. We mark out the pupil playing the King of France by giving them a balaclava helmet to wear; if a solider is 'injured', then they lie on the floor. The principles of generation are the instances of:

$x$ is wearing a balaclava helmet iff according to the pretence, $x$ is the King of France.

$x$ is lying on the floor iff according to the pretence, $x$ is injured.

Suppose I tell someone, 'The King of France is injured'. If they are aware of the game we are playing, then they will grasp the principles of generation and infer that the pupil wearing the balaclava helmet is lying on the floor. Things said within the pretence can communicate things about the real world, via our knowledge of the principles of generation. Quite generally, if a principle of generation takes the form

$p$ iff according to the pretence, $q$

then someone who says that $q$ within the pretence can communicate that it is the case that $p .7$

To help me explain how this story applies to mathematics, let me introduce some useful logical notation, which I will mix with ordinary English. For each sortal predicate, let ' $\exists 0 x F x$ ' mean ‘ $\exists x F x$ '. Informally, we can gloss ' $\exists 0 x F x$ ' as 'There are no $F \mathrm{~s}$ '. Let ' $\exists x 1 F x$ ' mean ' $\exists x(F \mathrm{x} \& \forall w(F w$

6 To avoid confusion, I should say that I make no distinction between pretence and make-believe.

7 Principles of generation might take other forms too, such as ' $p$ only if according to the pretence, $q$ ', but I will ignore that complication. 
$\supset w=x)$ )' - informally, 'There is exactly one $F$ '. Let ' $\exists 2 x F x$ ' mean ' $\exists x \exists y(F x$ \& Fy \& $\sim x=y$ \& $\forall w(F w \supset(w=x \vee w=y)))$ '一informally, 'There are exactly two $F \mathrm{~s}$ ' ‘ $\exists 3 \mathrm{x} F \mathrm{x}$ ', ‘ $\exists 4 \mathrm{x} F \mathrm{x}$ ', and so on, can be defined correspondingly.

I can now give an example of how Yablo applies Walton's ideas to mathematics (for more, see Yablo [1998] pp. 250-1, [2001]; [2002]; [2005]). Suppose that there are no numbers, and we do not believe there are any. Suppose further that we pretend that numbers exist; specifically, for every sortal predicate ' $F$ ', we pretend that there is such a thing as 'the number of $F \mathrm{~s}$ '. The pretence relies on the following principles of generation:

$\exists 0 x F x$ iff, according to the pretence, the number of $F \mathrm{~s}$ is zero.

$\exists 1 x F x$ iff, according to the pretence, the number of $F$ s is one.

$\exists 2 x F x$ iff, according to the pretence, the number of $F \mathrm{~s}$ is two.

And so on. Informally, we may gloss these as follows:

There are no $F \mathrm{~s}$ iff, according to the pretence, the number of $F \mathrm{~s}$ is zero.

There is exactly one $F$ iff, according to the pretence, the number of $F$ s is one.

There are exactly two $F$ s iff, according to the pretence, the number of $F$ s is two....

Yablo claims that this game of make-believe could bring expressive advantages. Suppose that I say, within the pretence, 'The number of sheep is zero'. Without believing in numbers, a hearer who grasps the principles of generation can come to believe that the world is such that my utterance 
is true in the pretence: they can come to believe that $\exists 0 x \mathrm{~S} x$ (where ' $\mathrm{S}$ ' is the predicate '...is a sheep'). In this case, I could easily have passed on the same thought without using the pretence: I could simply have asserted 'There are no sheep'. But sometimes it is much more difficult to pass on the thought we have. If within the pretence I say 'The number of sheep is square', I convey that things are such as to make this sentence true in the pretence; yet it is very difficult to find a short sentence which expresses the proposition that things are this way. (We could use the sentence 'There are no sheep, or there is exactly one sheep, or there are exactly four sheep, or there are exactly nine sheep, or there are exactly sixteen sheep....' But uttering this would take infinitely long.) Even if the sentence 'The number of sheep is square' is untrue, uttering it within the pretence can convey a nominalistic truth.

It is easy to see how the pretence delivers expressive advantages. None of ' $\exists 0 x F x$ ', ' $\exists 1 x F x$ ' etc. contain a singular term, but 'The number of $F \mathrm{~S}$ is zero', 'The number of $F \mathrm{~S}$ is one', etc. all do. We are thus able to quantify into that position. The quantified claim 'The number of sheep is square' (i.e. 'There is an $x$ such that the number of sheep is $x$ and $x$ is square') is equivalent to the infinite disjunction beginning:

The number of sheep is zero, or the number of sheep is one, or the number of sheep is four, or the number of sheep is nine, ....

And, via the principles of generation, this is true in the pretence just in case:

There are no sheep, or there is exactly one sheep, or there are exactly four sheep, or there are exactly nine sheep, or there are exactly sixteen sheep, or ....

Thus the principles of generation have the effect of giving us finite ways to express infinitely long 
disjunctions (cf. Yablo [2002], p. 231).8

Yablo comes close to saying that when we talk about numbers, we are actually participating in a game of make-believe: we do not believe in numbers, but we pretend that they exist, in order to expand our expressive capacities. However, he is aware that such a view would be implausible. Pretheoretically, it seems to us that we believe that $2+2=4$, that the number of dodos is zero, and so on. Perhaps that is compatible with the view that we are pretending, for perhaps we can believe and pretend the same proposition at the same time (cf. Austin [1958], p. 267 for some relevant examples). The more pressing problem is that it also seems to us that we are not pretending that $2+2=4$, that the number of dodos is zero, and so on. And that is inconsistent with the view (cf. Eklund [2007], section 4.1). In response to such worries, Yablo claims that we are not, strictly speaking, engaged in make-believe when we engage in mathematical discourse - rather, we are doing something that closely resembles make-believe. According to Yablo ([2001], p. 90): 'Making believe is an amalgam of (i) being as if you believe, and (ii) being that way through your deliberate efforts' (cf. pp. 97-9). Yablo explains that he is only attributing (i) to us, and calls this state of mind simulated belief. 9

Someone is simulating belief that $\mathrm{S}$ if although things are in relevant respects as if they believed that $\mathrm{S}$, when they reflect on the matter they find that they do not believe it; or at least are agnostic on the matter; or at least do not feel the propriety of their stance to depend on their belief that $\mathrm{S}$ if they have one. They do not believe that $\mathrm{S}$ except possibly per accidens. (p. 90)

8 There are other ways of expressing infinitely long disjunctions: for instance, substitutional quantification, or the tactic of giving the first few disjuncts followed by '...' (as in the text) or 'and so on'. Yablo would therefore be ill-advised to say that mathematical language allows us to communicate contents that could not have been articulated in any other way. Rather, his claim is that nominalistic contents are actually communicated in this way, because it offers some advantages over the others (e.g. brevity, suggestiveness). See (Yablo [1998], pp. 252-3, [2000a], pp. 296-7, [2002], p. 229, [2005], pp. 100-103, 112 n. 13).

9 He borrows this usage of the term 'simulation' from (Walton [1997]). 
Yablo offers examples of simulated belief, borrowed from Walton. They include: Einstein simulating belief in absolute motion whilst believing it is relative, a film-goer simulating belief that she is being attacked by a giant squid, and a dreamer simulating the belief that she is winning a Nobel Prize. Yablo claims (90) that whilst it is easy for us to tell whether we are making-believe (in the ordinary sense of 'making-believe'), it is much more difficult to tell whether we are simulating belief. Following Yablo, I will carry on using the terms 'pretence' and 'make-believe', stipulating that they are to be read in a wide sense that includes simulated belief.

To support his view, Yablo ([1998], p. 259 n. 75, [2000a] pp. 301-4, [2001], pp. 85-7, 8990, [2002], pp. 227-9) points to a large number of 'suggestive similarities' between mathematical and metaphorical talk. Yablo's argument is perhaps best understood as an inference to the best explanation: he points to various phenomena, argues that his account neatly explains them, and challenges his opponents to come up with superior alternative explanations.10 For instance, we treat

There are no sheep

and

(2) The number of sheep is zero

interchangeably: whenever we assent to one, we assent to the other, and we do not feel that the second makes a greater commitment than the first. Yet a moment's reflection suggests that the

$10 \mathrm{I}$ am assuming that Yablo is arguing that these phenomena can be neatly explained by the hypothesis that we are pretending. An alternative reading would take Yablo to be arguing that they can be neatly explained by the hypothesis that mathematical talk is metaphorical - in which case he would have to supply a separate argument that metaphor is best understood in terms of pretence. Yablo's use of the phrase 'metaphorical make-believe' leaves it rather unclear which of these he intends. For instance, he talks of 'similarities between platonic objects ... and creatures of metaphorical make-believe’ (Yablo [2000a], p. 301, italics removed). 
second sentence, but not the first, entails the existence of numbers. Yablo claims that his view accounts for this: when we say (2), we are speaking within the pretence. We do not believe that there such things as numbers, and so we do not believe the proposition the sentence expresses. But we do believe (1). We are happy to move from (1) to (2) because if (1) is true, then, in the pretence, (2) is true (see Yablo [2002], pp. 230-1). The children's game provides a parallel: children who say 'The King of France is injured' spend no time worrying that the King of France might not exist, since they are not committing themselves to the sentence's truth. Rather, they are committing themselves to its being true within the pretence; by the principles of generation, that is to commit themselves to the claim that the child in the balaclava is lying on the floor.

A related argument of Yablo's ([2000a], p. 278-9, [2000b], p. 200) relies on a thoughtexperiment. Suppose that you were to ask the Oracle of Philosophy — who is perfectly reliablewhether there are numbers. After a long pause, the Oracle replies in the negative. You go into university and tell all the people who are engaging in pure or applied mathematics to stop their activities at once. How would they reply? It seems that they would ignore you and carry on with what they are doing. Yablo's point could be extended beyond the groves of academe: everyone says things that imply the existence of numbers, and with the exception of some philosophers, no-one has much time for people informing us that there are no numbers. In short, we do not take the legitimacy of our mathematical discourse to depend on the existence of such things as the natural numbers. Yablo takes this to confirm his view that we do not pre-theoretically believe that there are numbers.

Yablo ([2000b]) also argues for his view by claiming that it solves a puzzle about ontology. On one hand, it seems that it is very hard to come up with successful a priori arguments for the existence of abstract objects (such as mathematical objects). But on the other, it seems that their existence can be established trivially by reflecting on the consequences of platitudes. For instance, the following argument seems to establish the existence of numbers:

There are as many $F \mathrm{~s}$ as $G \mathrm{~s}$ iff the number of $F \mathrm{~s}$ is equal to the number of $G$ s. 
There are as many dodos as dodos.

Therefore, there is a number.

Yablo ([2000b]: 224-6) responds to the puzzle by refusing to agree that the first premiss of this argument is literally true. On his view, our talk of numbers is from within the pretence that there are such things. The first premiss seems true- but that is because we confuse it with the following truth:

There are as many $F \mathrm{~s}$ as $G \mathrm{~s}$ iff according to the pretence the number of $F \mathrm{~s}$ is equal to the number of $G$ s. 11

\section{Psychological objections to Yablo's expressionism}

Stanley offers a sophisticated psychological objection to Yablo: 'the thesis that the same psychological capacity is involved in engaging in games of make-believe and grasping [mathematics] is likely to be subject to empirical refutation' ([2001], p. 47). To back up this claim, Stanley ([2001], pp. 48-9) appeals to autism. Children with autism do not tend to play games of make-believe (see Jarrold [2003]). Furthermore, people with autism find it difficult to cope with metaphor and other types of figurative speech. If mathematical language is figurative and forms part of a make-believe game, then we should expect people with autism to be incapable of participating in mathematical discourse. But that is not the case.

One possible reply to Stanley's objection is to claim that people with autism understand mathematical language in a special way: people who don't have autism use mathematical language figuratively, but people with autism take it literally; whereas people without the condition do not

11 The view presented in this section simplifies Yablo's views in two ways worth mentioning. (1) Yablo says that participants in mathematical discourse do not believe that there are numbers 'except possibly per accidens' ([2001], p. 90, italics removed). In other words, although the norms of mathematical discourse do not require us to believe the propositions its sentences express, they permit us to; Yablo is happy to allow that some participants-certain philosophers of mathematics, for instance - actually do so. (2) In his more recent work (e.g. [2006]), Yablo has invoked the notion of tactical presupposition in place of pretence. I will not be discussing this work here. 
believe that there is such a thing as the number of cows, people with autism do. Discussing this reply, Stanley claims that it

... does not entail that there is a detectable behavioural difference between the autistic person and those of us who ... pretend that there are numbers.... Someone who cannot engage in the make-believe we engage in when discussing arithmetic will nevertheless be able to add, subtract, and multiply. Though such a person will be operating under the misapprehension that she is adding and subtracting things that really exist, she will nevertheless be behaviourally no different from those of us who do engage in the make-believe. ([2001], p.

Stanley ([2001], p. 49) says that this reply is hopeless: it would not be sensible for an expressionist to claim that those who make-believe and those who are true believers are behaviourally indistinguishable. Before we reflect philosophically on the nature of mathematics, we are inclined to think that it is not make-believe. If there is no behavioural evidence to suggest that we are makingbelieve, then we should stick with our pre-theoretical view and reject the idea that we are pretending.

Stanley's reasoning here rests on a mistake: he assumes that anyone who makes this reply will deny that such a behavioural difference exists. But why should Yablo deny that there are behavioural differences between autistic and non-autistic participants in mathematical discourse? Yablo might claim that whilst members of both groups are successful participants in the discourse, they participate in it in different ways, with a corresponding difference in behaviour.

If he takes this route, it would be desirable for Yablo to specify how an autistic person's literal understanding of mathematical language might be reflected in their behaviour. Yablo's arguments for his view suggest some possible answers. Yablo observed that we do not feel that we are making a greater commitment when we assent to (2) than when we assent to (1). Perhaps people with autism $d o$ feel they are making a greater commitment when they utter (2) instead of (1). 
Another possible answer is suggested by Yablo's Oracle thought-experiment. It might turn out that people with autism have an unusual reaction to the Oracle scenario: perhaps they think that we should abandon mathematical discourse if mathematical objects turn out not to exist.

Thus, for all that Stanley has said, Yablo can reply to Stanley's autism objection by claiming that people with autism take mathematical language literally.12 But that leaves the simpler psychological objections mentioned in the previous section-and Yablo's response to these is less than satisfactory. Yablo responds to the charge of psychological implausibility by proposing that we are not (strictly speaking) pretending but rather simulating belief. He then claims that we can find it hard to detect whether we are simulating belief. This claim is ad hoc. In addition, it fails to explain why we mistakenly attribute beliefs to ourselves. And its negation is highly plausible. Recall Yablo's definition of simulated belief:

Someone is simulating belief that $\mathrm{S}$ if although things are in relevant respects as if they believed that $S$, when they reflect on the matter they find that they do not believe it; or at least are agnostic on the matter; or at least do not feel the propriety of their stance to depend on their belief that $\mathrm{S}$ if they have one. They do not believe that $\mathrm{S}$ except possibly per accidens. ([2001], p. 90)

Yablo's examples of simulated belief include Einstein simulating belief in absolute motion whilst believing motion is relative, a film-goer simulating belief that she is being attacked by a giant squid, and a dreamer simulating the belief that she is winning a Nobel Prize. I suggest that in all these cases the simulator is in a position to discover fairly easily that she is simulating belief, typically though finding on reflection that they do not believe the relevant proposition. We should expect Einstein to be well aware that he did not believe that motion is absolute; many (perhaps all) of us have had the

12 I offer a much more detailed discussion of Stanley's 'autism' objection to Yablo's theory and other pretence theories in my ([2010]). 
experience of discovering that we are dreaming; and it is hardly credible to think that film-goers would be uncertain, on reflection, whether or not they were genuinely under squid attack.

In many cases, we can distinguish states of simulated belief from states of belief fairly easily. Once one has the concepts of belief and simulated belief, one can reflect on whether one believes that $2+2=4$ and whether one is simulating belief that $2+2=4$ : and I suggest that such reflection confirms the view that one does not simulate it. Yablo has no explanation of why these reflections on our own psychological states should lead us astray.

Yablo writes:

Making believe is a conscious activity, or one easily brought to consciousness. Simulating is not. It may even come as a great surprise that one is simulating. It came as a great surprise to me to realize that although it was as if I believed that an invalid argument was one with countermodels, I did not really believe it save per accidens_-for I did not believe in models save per accidens. ([2001], p. 90)

This example does little to help Yablo escape the difficulty, even if we grant that in some cases it is hard to discover that one is simulating belief. It is striking that even in the example he gives, Yablo came to realize, on reflection, that he was simulating the belief: he did not come to think that he was believing without simulating. So the example does not make it any more plausible that, when I reflect on whether I am simulating belief that $2+2=4$, my reflection should deliver the wrong answer. Neither does help explain why my reflection would do this.

There are further psychological problems for Yablo's theory. One is that we arguably have authoritative knowledge of our own mental states; Yablo denies us such knowledge (Stanley [2001], pp. 46-7). Another problem concerns the speech acts we engage in when uttering declarative mathematical sentences. The child who utters 'The King of France is injured' does not assert that the King of France is injured (they may well know that there is no present King of France); rather, they 
are speaking from within the pretence. According to Yablo's theory, the same goes for us when we appear to make mathematical assertions. But this is implausible. Suppose we tack a mathematical conjunct on to an ordinary assertion: 'Obama is President and $2+2=4$ '. We do not feel any shift of gears half way through the sentence. 13

So although Yablo can meet the autism objection, his view still runs into psychological trouble. Expressionists should look for an alternative solution to the communication problem. I offer one in the next section.

\section{Introducing belief expressionism}

Suppose that Yablo takes the reply to the autism objection I have recommended and says that people with autism do not pretend that there are numbers, but believe that they exist. Ordinary mathematical talk, on Yablo's view, is governed by principles of generation such as the instances of these:

There are no $F \mathrm{~s}$ iff according to the pretence, the number of $F \mathrm{~s}$ is zero.

There is exactly one $F$ iff, according to the pretence, the number of $F$ s is one.

There are exactly two $F$ s iff, according to the pretence, the number of $F$ s is two.14

According to my recommended reply, people with autism do not engage in the pretence: where most people pretend, they believe. In learning how to talk about numbers, they do not grasp the principles of generation. People who don't have autism grasp the principle that there are no $F$ s iff it is true in the pretence that the number of $F \mathrm{~s}$ is zero. People with the condition, on the other hard, come to

13 (Tallant [forthcoming]) argues against pretence accounts of mathematics by appeal to results from neuroscience.

14 Recall that the left-hand sides of these biconditionals are meant as informal glosses of the claims ' $\exists 0 x F x$ ', ' $\exists 1 x F x$ ', and ' $\exists 2 x F x$ '. 
believe that there are no $F \mathrm{~s}$ iff the number of $F \mathrm{~s}$ is zero. They gain beliefs such as the following:

There are no $F \mathrm{~s}$ iff the number of $F \mathrm{~s}$ is zero.

There is exactly one $F$ iff the number of $F$ s is one.

There are exactly two $F$ s iff the number of $F$ s is two.

These are just the principles of generation minus the occurrences of 'according to the pretence'.

Yablo's make-believe game offered expressive advantages: by claiming within the pretence 'The number of sheep is square', I can efficiently convey a nominalistic belief about sheep to hearers who are also pretending. They will gain the belief that things are such as to make my utterance true within the pretence. We should note that my utterance can also convey the same nominalistic belief to autistic hearers. They will gain that belief because they think it must be true in order for my utterance to be true. And the same point obtains more generally. Whenever those within the pretence hear a mathematical sentence, and as a result come to believe that things are such as to make the mathematical sentence true within the pretence, people with autism come to believe that things are such as to make the mathematical sentence true. So the same content can be conveyed without the use of pretence.

This suggests a new way for expressionists to explain how mathematical language helps us to communicate nominalistic beliefs. Let me introduce belief expressionism. The belief expressionist does not claim that we are making-believe or simulating when we talk about numbers. Rather, they claim that the description I have just given of how people with autism engage with mathematics is true, not just of people with autism, but of all of us.15 We all believe that there are numbers, and we all believe that there are links between the way things are and the way numbers are; when we hear

15 With the exception of some philosophers of mathematics: see the footnote after next. 
claims about numbers, we typically come to believe them, and we draw on our beliefs about the links to reach conclusions about the physical world. The claim that we believe in numbers is a common one among nominalists. What is new in belief expressionism is its explanation of how mathematical language functions as a communicational aid.

Let me give an example. Suppose someone says, 'The number of kangaroos in Ely is zero'. We all share the belief that the number of kangaroos in Ely is zero iff there are no kangaroos in Ely. So it is no surprise that the hearers come to believe that there are no kangaroos in Ely. We simply deduce this truth from the claim we hear and the belief we already have.

In this case, one could simply have said 'There are no kangaroos in Ely'. But the same mechanism allows one to communicate nominalistic beliefs that cannot easily be conveyed without quantifying over numbers. The belief expressionist can explain how 'The number of sheep is square' conveys a nominalistic belief: they can say that we already believe that:

The number of sheep is square iff there are exactly no sheep, or there is exactly one sheep, or exactly four sheep, or exactly nine ....

When we are told that the left-hand side of this biconditional is true, we deduce that the right-hand side is, thus acquiring a nominalistic belief that couldn't be directly communicated in a finite sentence.

It seems that anything which can be conveyed by the means of pretence can be conveyed without it. This is evident in cases where Yablo invokes only a single principle of generation. According to his theory, we hear ' $q$ ' and infer ' $p$ ' using the principle of generation

$p$ iff according to the pretence, $q$.

The belief expressionist says that we believe that we infer ' $q$ ' from ' $p$ ' because we believe that $p$ iff 
$q$.

Consider a more complicated case where Yablo's explanation appeals to more than one principle of generation. Suppose we know the following principles of generation:

P1 $\quad p$ iff according to the pretence, $q$.

P2 $\quad r$ iff according to the pretence, $s$.

When we hear ' $q$ and $s$ ', we infer ' $p$ and $r$ '. Yet this conclusion does not follow directly from what we have heard and the principles of generation alone. Presumably Yablo will claim that we reason as follows:

$1 \quad$ According to the pretence, $q$ and $s$.

2 According to the pretence, $q$.

3 According to the pretence, $s$.

$4 \quad p .($ from 2 , by $\mathrm{P} 1)$

$5 \quad r$. (from 3, by P2)

$6 \quad p$ and $r .($ from 4,5$)$.

For this reasoning to be valid, 2 and 4 must follow from 1, so the 'According to the pretence' operator must be closed under and-elimination. The argument involves some reasoning within the scope of the operator before deploying the principles of generation to reach conclusions outside its scope.

The belief expressionist counterpart of this reasoning simply uses and-elimination itself. The beliefs corresponding to $\mathrm{P} 1$ and $\mathrm{P} 2$ are as follows:

P1' $\quad p$ iff $q$. 
P2' $\quad r$ iff $s$.

and the reasoning runs like this:

$1^{\prime} \quad q$ and $s$.

$2^{\prime} \quad q .\left(\right.$ from $\left.1^{\prime}\right)$

$3^{\prime} \quad$ s. (from $\left.1^{\prime}\right)$

$4^{\prime} \quad$ p. $\left(2^{\prime}\right.$, by $\left.\mathrm{P} 1^{\prime}\right)$

$5^{\prime} \quad r .\left(3^{\prime}\right.$, by $\left.\mathrm{P} 2^{\prime}\right)$

$6^{\prime} \quad p$ and $r$. (from $\left.4^{\prime}, 5^{\prime}\right)$.

And this is clearly valid. So deleting the occurrences of 'According to the pretence' in the argument and in the principles of generation has turned one valid argument into another.

The same holds more generally. Suppose (a) that the 'According to the pretence' operator is closed under logical implication: in other words,

If ' $p$ ' logically implies ' $q$ ', then: if according to the pretence, $p$, then according to the pretence, $q$.

And suppose (b) that the inferences Yablo posits in which we draw conclusions about the nominalistic world from things said in the pretence have the following features: they begin with reasoning in the scope of the 'According to the pretence' operator which appeals only to the closure of the operator under logical implication; then they deploy the principles of generation to reach conclusions outside the scope of the operator. (For instance, 1-6 is an argument of this type.) It follows from these suppositions that every valid inference Yablo posits has a valid pretence-free counterpart. 
To see this, suppose we have a valid inference such as 1-6. Now consider the corresponding argument formed by deleting every instance of 'According to the pretence' from the argument and the principles of generation. The initial steps, governed by the operator, will remain valid, because here the initial reasoning appealed only to the closure of the operator under logical implication. Valid deduction within its scope will thus be replaced by valid unprefixed deduction. And the rest of the argument will remain valid. Suppose, for instance, that we move from 'According to the pretence, $q$ ' to ' $p$ ' via the principle of generation $\mathrm{P} 1$. The corresponding argument will move from ' $q$ ' to ' $p$ ' via the background belief ' $q$ iff $p$ '; such steps are valid instances of modus ponens. Thus, given (a) and (b), the corresponding argument will be valid if the original is.

Moreover, both (a) and (b) are highly plausible. The view that such operators are closed under logical implication is an attractive one (see Lewis [1978]).16 And (b) records the shape that Yablo regards these inferences as having. This is a popular approach among fictionalists: principles of generation act as 'bridge principles' allowing us to move between beliefs about what is the case in the pretence and beliefs about the real world (see Nolan [2005], pp. 211-3). In addition, (b) claims that the reasoning within the scope of the operator appeals appeals only to its closure under logical implication. Since it is hard to see what other rules would be needed, this is plausible too. It is therefore likely that any nominalistic belief which can be conveyed by the means of pretence can be conveyed without it. In particular, it seems that the belief expressionist can explain all the communication Yablo explains. Moreover, the belief expressionist explanations are simpler.

I argued in the previous section that Yablo's view runs into psychological difficulties. For instance, it is implausible to think that we simulate belief in mathematical propositions; Yablo's response to this problem is ad hoc and implausible. In contrast, belief expressionism does not face any of these problems. As the name suggests, the view avoids any assertion that we are makingbelieve or simulating belief when we engage in mathematical discourse. This should endear it to

16 Presumably Yablo does not need to ascribe complicated reasoning to us. So all that is really needed here is the weaker claim that the operator is closed under simple (or obvious) logical implication. This approach may appeal to Waltonians: cf. (Walton [1990] chapter 4), on the 'disorderly behaviour of the machinery of generation' (p. 184). 
philosophers who find Yablo's view hard to swallow. Where Yablo talks of simulation, the belief expressionist simply talks about ... belief. And the beliefs in question are ones which it seems eminently plausible to ascribe to us. Those corrupted by philosophical reflection aside, who would deny that the number of kangaroos is zero just in case there are no kangaroos? Or that the number of kangaroos is one just in case there is a kangaroo and no other kangaroos? Such claims seem platitudinous. And the belief expressionist claims that when we appear to assert that $2+2=4$, that is just what we are doing. 17

Belief expressionism therefore seems an attractive choice for expressionists. If you want to claim that mathematics is useful in science because it helps us to communicate, then you ought to explain how mathematical language brings this benefit. Yablo and the belief expressionist offer competing accounts. It seems that any communication Yablo can explain, the belief expressionist can also explain — and more simply. Moreover, the belief expressionist avoids implausible claims about our psychological states and speech acts. The belief expressionist response to the communication problem therefore demands serious consideration.

\section{Objections and replies}

\subsection{Yablo’s likely response}

How would Yablo respond to belief expressionism? I think he would challenge belief expressionists to account for the phenomena which he points to in support of his position. For instance, we treat

17 What about those who have been corrupted by philosophical reflection? Many philosophers of mathematics disbelieve in numbers or suspend judgement on their existence: if they are consistent, these philosophers will never believe that the number of $F \mathrm{~s}$ is zero, even when they believe that there are no $F \mathrm{~s}$ (that is, even when they believe that $\exists 0 \mathrm{x} F \mathrm{x}$ ); so, if they are consistent, they will not believe the biconditional 'The number of $F \mathrm{~s}$ is zero just in case there are no $F \mathrm{~s}$ '. The same goes for many of the other biconditionals which belief expressionists claim we believe. Belief expressionists should restrict their account so that they make no claims about the mathematical practice of these philosophers. This is no embarrassment: it is common sense to think that reflection on a practice sometimes leads one towards an unusual mode of engagement in it. Perhaps the same goes for some non-philosophers too. 
(1) There are more sheep than cows

and

interchangeably: whenever we assent to one, we assent to the other, and we do not feel that the second makes a greater commitment than the first.

Belief expressionists have an obvious explanation to offer, piggy-backing on Yablo's. As we have seen, Yablo explains the phenomenon by saying that if (1) is true, then, in the pretence, (2) is true. Correspondingly, belief expressionists will claim that we pre-theoretically believe that (1) is true iff (2) is true. This explains why we treat them interchangeably. If we assume - as is plausiblethat we take it to be necessary that (1) is true iff (2) is, then we can explain why we do not feel the second makes a greater commitment than the first. We think that whenever (1) is true, (2) will be true as well; so if (1) is true, then there are numbers; so both (1) and (2) imply that there are numbers.18

Belief expressionists can also deal with Yablo's Oracle argument. If we announced the discovery that there are no mathematical objects, mathematicians would not take this to threaten the legitimacy of their work. According to Yablo, this suggests that mathematicians do not believe that there are numbers. But, as Rosen and Burgess ([2005], p. 532) point out, there are alternative explanations which deserve consideration. For instance, perhaps mathematicians would react to the announcement by dropping their belief that there are numbers and replacing it with the pretence that they exist. It is far from obvious that Yablo's explanation is superior to this one.

Recall Yablo's puzzle about ontology. It seems very difficult to come up with a priori arguments for the existence of abstract objects; but then again it also seems trivially easy:

18 Burgess and Rosen ([2005], p. 531) make a similar point: they suggest that our willingness to interchange 'There are $n F \mathrm{~s}$ ' and 'The number of $F \mathrm{~s}$ is $n$ ' can be explained by saying that 'they are equivalent modulo a background theory whose truth is not ... in question'. My point is that belief expressionists can benefit from this kind of move. 
There are as many $F \mathrm{~s}$ as $G \mathrm{~s}$ iff the number of $F \mathrm{~s}$ is equal to the number of $G \mathrm{~s}$.

There are as many dodos as dodos.

Therefore, there is a number.

Yablo explains the attraction of this argument by claiming that we confuse the first premiss with the following truth:

There are as many $F \mathrm{~s}$ as $G$ s iff according to the pretence the number of $F \mathrm{~s}$ is equal to the number of $G$ s.

The belief expressionist can explain the attraction of the argument just by saying that we believe the first premiss. Even if there are no numbers, this belief is useful for the representational advantages it confers. Once again, this explanation piggy-backs on Yablo's: where Yablo uses a principle of generation, the belief expressionist uses a corresponding belief.

Yablo's arguments merit a much more detailed assessment than I have been able to give here. It remains to be shown that the belief expressionist can deal with all the phenomena to which Yablo appeals. Indeed, Yablo lists so many 'suggestive similarities' between mathematical and metaphorical language, in addition to his other arguments, that this would be a major research project.19 Moreover, I have concentrated exclusively on arithmetical language: I have not tried to tackle the work of extending the belief expressionist story to other areas of mathematics, such as talk

19 Burgesss and Rosen ([2005], pp. 531-4) offer some alternative explanations of some of the phenomena (see previous footnote for an example). Belief expressionists may be able to appropriate these. (There is some irony here: Burgess and Rosen's paper is devoted to attacking nominalism, but it actually offers defensive weaponry to some nominalists: namely, nominalist belief expressionists.)

Stanley ([2001], p. 50) writes: 'Yablo's analogies are contentious, in that many of them only someone with nominalist leanings would find compelling'. This remark deserves further consideration: if some or all of the phenomena Yablo appeals to turn out not to be genuine, then this will not only weaken Yablo's argument, but also make the belief expressionist's task easier. 
of masses, charges, or other physical quantities. Neither have I addressed what belief expressionists should say about the role of mathematics in inference, discovery, or explanation.20 So my conclusion is simply that expressionists should take belief expressionism seriously; at present, it is an open question whether it is superior to Yablo's brand of expressionism. I finish by defending this conclusion from another line of objection.

\subsection{Charity}

Nominalist belief expressionists deny that there are mathematical objects. They claim that we pretheoretically believe that $2+2=4$, and then go on to deny that $2+2=4$, on the ground that there are no such things as numbers. The same goes for many other mathematical beliefs. It might be argued that it is uncharitable to deny so many apparently obvious beliefs; perhaps no philosophical theory which diverges so far from common opinion could be acceptable.

Two issues arise here: (i) Do these considerations refute nominalist belief expressionism? (ii) Do these considerations show that Yablo's theory has an advantage over nominalist belief expressionism?

The methodological issues raised by (i) are discussed in detail in (Daly and Liggins [2010], section 6), so here I can be brief. Principles of charity come in different strengths. A strong, Davidsonian, version says that we should attribute untrue beliefs only given overwhelming evidence. But this sort of charity is 'likely to block understanding of human behaviour and impede progress toward improving it' (Thagard and Nisbett [1983], pp. 250-1; cf. Williamson [2007], pp. 260-70). Weaker and more plausible principles of charity are quite compatible with belief expressionism: for example, the principle that we should not attribute untrue beliefs to people unless we can explain why they formed them. The nominalist belief expressionist can explain why we formed our mathematical beliefs by pointing out that they are useful: for instance, they enable us to communicate nominalistic claims, in the way set out in section 4. Furthermore, the belief

20 For a discussion of the inferential role of mathematics in connection with Melia's work, see (Liggins [forthcoming]). 
expressionist can point out that the question of whether there are numbers is a difficult one, on which the experts disagree. We should not expect common sense to have already investigated such an issue and come down on the right side. So worries about charity do not sink belief expressionism. 21

Turning now to (ii), it may seem initially that Yablo's theory conforms more closely to common sense than nominalist belief expressionism does. Unlike the nominalist belief expressionist, Yablo attributes no mathematical belief to us at all, and so does not attribute any untrue mathematical beliefs to us. However, Yablo's theory still incorporates an error theory: he attributes untrue psychological beliefs to us. For instance, we think, pre-theoretically, that we believe that $2+2=4$; but according to Yablo that belief is false. And the same goes for many other mathematical propositions. If the widespread attribution of untrue beliefs is a theoretical vice, it is one which Yablo and the belief expressionist both indulge in. It is therefore hard to see that Yablo's theory has any advantage over belief expressionism on this score. Moreover, the claim that we are mistaken about which psychological states we are in when we engage in mathematical discourse is less plausible than the claim that we are mistaken about a difficult and controversial metaphysical question; and, as we saw in section 3, Yablo's attempt to explain why we are mistaken about our own psychological states is less than compelling. So nominalist belief expressionism actually has the advantage over Yablo's view here.

\section{Conclusion}

Expressionists claim that mathematics is useful in science because it helps us to say things about concrete objects which it would otherwise be more difficult, or perhaps impossible, for us to say. Expressionists owe us an account of how mathematics helps us to say these things. So far, the only expressionist to provide us with one is Yablo. In his view, when we talk about numbers, we are actually participating in something very much like a game of make-believe. I have argued that belief

21 Other methodological objections to error theories are considered and rejected in (Daly and Liggins [2010]). 
expressionism provides a simpler and more plausible account of how mathematics helps us to articulate our thoughts. I commend it to expressionists.

Philosophy, School of Social Sciences

University of Manchester

Oxford Road, Manchester, M13 9PL, UK

david.liggins@manchester.ac.uk

\section{Acknowledgements}

I am grateful to audiences in Cambridge, Frankfurt, Leeds, Oxford, Sheffield, and Southampton, where I received many helpful questions and comments. Thanks also to Anna Mahtani, Catharine Abell, Chris Daly, Graham Stevens, Steve Yablo, and a number of anonymous referees.

\section{References}

Austin, J. L. [1958]: 'Pretending', Proceedings of the Aristotelian Society, Supplementary Volume, 32, pp. 261-78.

Balaguer, M. [1998]: Platonism and Anti-Platonism in Mathematics, New York: Oxford University Press.

Burgess, J., and Rosen, G. [1997]: A Subject with No Object: Strategies for Nominalistic Interpretation of Mathematics, Oxford: Clarendon Press.

Colyvan, M. [2002]: 'Mathematics and Aesthetic Considerations in Science', Mind, 111, pp. 69-74.

Crimmins, M. [1998]: 'Hesperus and Phosphorus: Sense, Pretence, and Reference', Philosophical Review, 107, pp. 1-47.

Daly, C. and Liggins, D. [2010]: 'In Defence of Error Theory', Philosophical Studies, 149, pp. 20930. 
Eklund, M. [2007]: 'Fictionalism', in E. Zalta (ed.), Stanford Encyclopedia of Philosophy (Summer 2007 Edition), <plato.stanford.edu/archives/sum2007/entries/fictionalism/>

Everett, A. and Hofweber, T. (eds) [2000]: Empty Names, Fiction and the Puzzles of Non-Existence, Stanford: CSLI Publications.

Field, H. [1980]: Science without Numbers, Oxford: Blackwell.

Field, H. [1989]: Realism, Mathematics and Modality, Oxford: Blackwell.

Field, H. [1998]: 'Mathematical Objectivity and Mathematical Objects'. In Laurence and Macdonald (eds) [1998], pp. 387-403. Reprinted in Field, H., 2001, Truth and the Absence of Fact, Oxford: Clarendon Press, pp. 315-31.

Jarrold, C. [2003]: ‘A Review of Research into Pretend Play in Autism', Autism, 7, pp. 379-390.

Kalderon, M. (ed.) [2005]: Fictionalism in Metaphysics, Oxford: Clarendon Press.

Kroon, F. [2000]: 'Negative Existentials', in Everett and Hofweber (eds) [2000], pp. 95-116.

Laurence, S. and Macdonald, C. (eds) [1998] Contemporary Readings in the Foundations of Metaphysics, Oxford: Blackwell.

Leng, M. [2010]: Mathematics and Reality, Oxford: Oxford University Press.

Lewis, D. [1978]: 'Truth in Fiction', American Philosophical Quarterly, 15, pp. 37-46.

Liggins, D. [2010]: 'The Autism Objection to Pretence Theories', Philosophical Quarterly, 60, pp. $764-82$.

Liggins, D. [forthcoming]: 'Weaseling and the Content of Science', Mind.

Melia, J. [1995]: 'On What There's Not', Analysis, 55, pp. 223-9.

Melia, J. [1998]: 'Field's Programme: Some Interference', Analysis, 58, pp. 63-71.

Melia, J. [2000]: 'Weaseling Away the Indispensability Argument', Mind, 109, pp. 455-79.

Melia, J. [2002]: 'Response to Colyvan', Mind, 111, pp. 75-8.

Nolan, D. [2005]: 'Fictional Attitudes about Fictional Matters', in Kalderon (ed.) [2005], pp. 204-33.

Rosen, G. and Burgess, J. [2005]: 'Nominalism Reconsidered', in Stewart Shapiro (ed.) 2005: 51535. 
Shapiro, S. (ed.) [2005]: The Oxford Handbook of Philosophy of Mathematics and Logic, New York: Oxford University Press.

Stanley, J. [2001]: 'Hermeneutic Fictionalism', Midwest Studies in Philosophy, 25, pp. 36-71.

Tallant, J. [forthcoming]: 'Mathematics, Pretence, and Cognitive Neuroscience', British Journal for the Philosophy of Science.

Thagard, P. and Nisbett, R. E. [1983]: 'Rationality and Charity', Philosophy of Science, 50, pp. 25067.

Walton, K. [1990]: Mimesis as Make-Believe, Cambridge, MA: Harvard University Press.

Walton, K. [1993]: 'Metaphor and Prop Oriented Make-Believe'. European Journal of Philosophy 1: 39-57. Reprinted in Kalderon (ed.) [2005], pp. 65-87.

Walton, K. [1990]: Mimesis as Make-Believe: On the Foundations of the Representational Arts, Harvard: Harvard University Press.

Walton, K. [1997]: 'Spelunking, Simulation and Slime: On Being Moved by Fiction', in Hjort, M. and Laver, S. (eds) Emotion and the Arts, 1997, New York: Oxford University Press, pp. 3749.

Wigner, E. [1960]: 'The Unreasonable Effectiveness of Mathematics in the Natural Sciences', Communications in Pure and Applied Mathematics, 13, pp. 1-14.

Williamson, T. [2007]: The Philosophy of Philosophy, Oxford: Blackwell.

Yablo, S. [1998]: 'Does Ontology Rest on a Mistake?', Proceedings of the Aristotelian Society, Supplementary Volume, 72, pp. 229-61.

Yablo, S. [2000a]: 'A Paradox of Existence', in Everett and Hofweber (eds) [2000], pp. 275-312.

Yablo, S. [2000b]: 'Apriority and Existence', in Boghossian, P. and Peacocke, C. (eds), 2005, New Essays on the A Priori, Oxford: Clarendon Press, pp. 197-228.

Yablo, S. [2001]: 'Go Figure: A Path Through Fictionalism', Midwest Studies in Philosophy, 25, pp. $72-102$.

Yablo, S. [2002]: ‘Abstract Objects: A Case Study’, Philosophical Issues, 12, pp. 220-40. 
Yablo, S. [2005]: 'The Myth of the Seven', in Kalderon (ed.) [2005], pp. 88-115.

Yablo, S. [2006]: 'Non-Catastrophic Presupposition Failure', in Thomson, J. J. and Byrne, A. (eds), 2006, Content and Modality: Themes from the Philosophy of Robert Stalnaker. Oxford: Clarendon Press: pp. 164-190. 